\title{
Intraoperative airway cuff pressure monitoring: are we doing it right?
}

\author{
Vihara Dassanayake ${ }^{I^{*}}$ \\ Senior Lecturer in Anaesthesiology and Consultant Anaesthetist \\ Department of Surgery, Faculty of Medicine, University of Colombo. Sri Lanka.
}

\begin{abstract}
Background: Insertion of endotracheal tubes (ETT) and supra-glottic airway devices (SGA) are common practice amongst anaesthesiologists when administering general anaesthesia to facilitate numerous surgical procedures. In an era where quality of patient care and patient safety takes precedence, monitoring of intraoperative cuff pressure of an airway device remains an essential component in anaesthetic practice.

Methods: Data was collected through a single page questionnaire from postgraduate trainees in anaesthesiology involved in administering general anaesthesia for elective surgical procedures over a three- month period at the National Hospital of Sri Lanka. Study population included all patients undergoing elective surgical procedures requiring an endotracheal tube (ETT- high volume low pressure cuff) or a supra-glottic airway (SGA) device to facilitate ventilation under general anaesthesia.

Data was analysed using SPSS version 22.0 and was expressed as median, inter-quartile range [IQR], frequency, percentage and $95 \%$ confidence interval (CI) where appropriate. Correlation test was used to determine the relationship between cuff pressure and size of airway device. A non-parametric test was used to measure the significance between various carrier gas combinations and cuff pressure values for both ETT and SGA devices.

Results: 196 completed questionnaires were received over a three-month period. Mean age of the patients were 44.1 years and $64.8 \%$ were females. Majority $(53.6 \%)$ were ASA (American Society of Anaesthesiologists) grade I. ETT were used in $82.7 \%$ and SGA devices were used in $13.8 \%$ of cases. ETT's were used for laparotomies/laparoscopic procedures in $32.7 \%$ followed by $22.2 \%$ in gynaecological surgeries and $17.9 \%$ in thyroid and related surgery. SGA devices were mostly used for gynaecological procedures (40.7\%). Theatre supporting staff was responsible for the initial cuff inflation in $83.2 \%$.

During the initial cuff pressure measurement $58.6 \%$ of endotracheal tubes had pressures within the recommended level $\left(20-30 \mathrm{cmH}_{2} \mathrm{O}\right) .33 .3 \%$ had cuff pressures of $>30 \mathrm{cmH}_{2} \mathrm{O}$ while $8 \%$ had cuff pressures of $<20 \mathrm{cmH}_{2} \mathrm{O}$. In contrast to the above findings, the recommended cuff pressure values for SGA devices was achieved only in $29.6 \%$ and in $37 \%$ the cuff pressures were more than $70 \mathrm{cmH}_{2} \mathrm{O}$ which was alarming. $33.3 \%$ had cuff pressure values less than recommended.
\end{abstract}

Conclusion and Recommendations: It is evident that cuff pressure values in both endotracheal tubes and supra-glottic devices were not optimal and it was more so with the latter. Adherence to current evidence-based recommendations to ensure patient safety is vital in anaesthetic practice. To overcome the above problem, cuff pressure must be monitored at the commencement of surgery and at hourly intervals during general anaesthesia, which will identify under or over-inflation of the cuff and minimize related complications. Similarly, a sign-post to remind the anaesthetist, "Have you checked the cuff pressure today?" should be displayed in all operating theatres next to the airway trolley to avoid failure to reach standards.

Keywords: cuff pressure; endotracheal tubes; supra-glottic airway device; patient safety; monitoring

*Correspondence: Vihara Dassanayake

E mail: viharadassanayake@gmail.com

iD https://orcid.org/0000-0001-6582-0577

Received: $30 / 12 / 2017$

Accepted: 31/03/2018

DOI: http:/doi.org/10.4038/sljav26i2.8308

\section{Introduction}

The Royal College of Anaesthetists in 2010 have recommended that cuff pressure should be monitored, controlled and documented ${ }^{1}$ in airway devices such as endotracheal tubes (ETTs) and supra-glottic airway devices (SGA) used during general anaesthesia to facilitate ventilation in patients undergoing surgery. 
An ETT is inserted to secure the airway when administering general anaesthesia during surgery. The risk of aspiration of gastric contents in to the lower airway is a known complication following general anaesthesia since patients' protective reflexes are abolished after the loss of consciousness. During short surgical procedures and in selected group of patients the airway can also be secured using a SGA device.

Over-inflation of endotracheal tube cuffs can result in pharyngo-laryngeal-tracheal complications. ${ }^{1}$ Manufacturers of supra-glottic airway devices such as first and second generation laryngeal masks have also recommended target cuff pressure limits to minimize airway related complications. ${ }^{1}$ Despite current recommendations intraoperative cuff pressure monitoring is not standard practice in most operating theatres unlike in intensive care units. ${ }^{1}$

As the initial step, based on these recommendations a self-administered questionnaire on current practice was administered randomly to 36 post-graduate trainees in anaesthesiology, involved in administering anaesthesia under consultant supervision for elective surgical procedures during routine theatre lists at the National Hospital of Sri Lanka.

Seventy eight percent $(77.7 \%)$ of the trainees had 2-5 years of experience in anaesthesia and 19\% had more than 5 years of experience and probably were very skilful in insertion of airway devices. $33.3 \%$ were final year registrars in anaesthesiology. $83 \%$ responders stated that intraoperative cuff pressure monitoring was important but surprisingly $16 \%$ stated that it was not important. The striking feature was that all responders in the latter group had more than 3 years of experience in anaesthesia, which was of concern. $52.7 \%$ occasionally measured cuff pressure during surgery and $25 \%$ never measured intraoperative cuff pressure.

$44.4 \%$ were not aware of the correct ETT cuff pressure limits and $69.4 \%$ did not know the recommended cuff pressure value for a SGA device. Most post-graduate trainees were unaware of the availability of such devices as $75 \%$ stated that it was not available or that they did not know if such devices were present in the operating theatres that they worked, on a routine basis. Most trainees stated that they themselves would inflate the cuff and the rest of them stated that the theatre supporting staff would assist them during this procedure. Documentation of intraoperative cuff pressure was occasionally done by $52.7 \%$ and $38.8 \%$ never felt it was important to document cuff pressure in the anaesthetic record.

Based on their existing knowledge this project was taken a step further, to audit and assess the initial cuff pressure after securing the airway of a patient undergoing surgery during routine theatre lists for elective surgical procedures in all operating theatres conducting such lists and where cuff pressure monitoring apparatus was available.

\section{Material and Methods}

This was a population-based audit with prospective and consecutive data collection been done by postgraduate trainees administering anaesthesia for patients undergoing elective surgeries in all general theatres at the National Hospital of Sri Lanka. A single page selfadministered questionnaire was distributed to all post-graduate trainees administering general anaesthesia for elective surgical procedures over a three -month period. Data was extracted from the questionnaire which was filled by the postgraduate trainee who was responsible for administering the anaesthetic. Though current guidelines recommend the routine measurement of cuff pressure during anaesthesia it is found that in most instances there is non-adherence to these guidelines. By engaging themselves in this audit the postgraduate trainees were compelled to measure the cuff pressure, ensuring patient safety. One hundred and ninety-six (196) duly completed data collection sheets were obtained during this three- month period.

Ethics approval was obtained from the Ethics Review Committee at the National Hospital of Sri Lanka (AAJ/ETH/COM/2017-06) and data was collected after obtaining consent from the respective consultant anaesthetists. Data was analysed using SPSS version 22.0. 
Dassanayake. Sri Lankan Journal of Anaesthesiology: 26(2):137-143(2018)

\section{Results}

Table 1: Types of surgery performed

\begin{tabular}{|c|c|c|c|}
\hline Type of Surgery & Frequency & $\%$ & $95 \% \mathrm{CI}$ \\
\hline \multicolumn{4}{|l|}{$\begin{array}{l}\text { Endotracheal } \\
\text { Tube(ETT) }\end{array}$} \\
\hline $\begin{array}{l}\text { Thyroid and related } \\
\text { surgery }\end{array}$ & 29 & 17.9 & $11.5-24.8$ \\
\hline $\begin{array}{l}\text { Laparotomy/laparo } \\
\text { scopy (abdominal) }\end{array}$ & 53 & 32.7 & $26.3-42.0$ \\
\hline $\begin{array}{l}\text { Other general } \\
\text { surgical procedures }\end{array}$ & 17 & 10.5 & $5.4-16.2$ \\
\hline $\begin{array}{l}\text { Gynaecological } \\
\text { procedures }\end{array}$ & 36 & 22.2 & $15.8-29.1$ \\
\hline Urology & 4 & 2.5 & $0.6-6.0$ \\
\hline Breast surgery & 7 & 4.3 & $1.2-7.6$ \\
\hline ENT & 4 & 2.5 & $0.6-5.1$ \\
\hline $\begin{array}{l}\text { Vascular } \\
\& \text { Transplant } \\
\text { surgery }\end{array}$ & 12 & 7.4 & $3.7-11.3$ \\
\hline Total & 162 & 100.0 & \\
\hline \multicolumn{4}{|l|}{$\begin{array}{l}\text { Supra-glottic } \\
\text { Airway device } \\
\text { (SGA) }\end{array}$} \\
\hline $\begin{array}{l}\text { Thyroid and related } \\
\text { surgery }\end{array}$ & 1 & 3.7 & $0.0-12.5$ \\
\hline $\begin{array}{l}\text { Other general } \\
\text { surgical procedures }\end{array}$ & 9 & 33.3 & $14.4-53.6$ \\
\hline $\begin{array}{l}\text { Gynaecological } \\
\text { procedures }\end{array}$ & 11 & 40.7 & $20.1-63.8$ \\
\hline Urology & 3 & 11.1 & $0.0-24.0$ \\
\hline Breast surgery & 1 & 3.7 & $0.0-12.9$ \\
\hline ENT & 1 & 3.7 & $0.0-13.6$ \\
\hline $\begin{array}{l}\text { Vascular } \\
\text { \&Transplant } \\
\text { surgery }\end{array}$ & 1 & 3.7 & $0.0-12.5$ \\
\hline Total & 27 & 100.0 & \\
\hline
\end{tabular}

\section{$95 \% \mathrm{CI}=$ Confidence Interval}

Table 2: Demographic details of the patient population $(\mathrm{n}=196)$

\begin{tabular}{|l|r|r|}
\hline Variable & Frequency & $\%$ \\
\hline Age in years & & \\
\hline$\leq 20$ & 9 & 4.6 \\
\hline $21-30$ & 26 & 13.3 \\
\hline $31-40$ & 51 & 26.0 \\
\hline $41-50$ & 48 & 24.5 \\
\hline $51-60$ & 32 & 16.3 \\
\hline$>60$ & 30 & 15.3 \\
\hline Sex & & 35.2 \\
\hline Male & 69 & 64.8 \\
\hline Female & 127 & $\mathbf{1 0 0 . 0}$ \\
\hline Total & $\mathbf{1 9 6}$ & \\
\hline
\end{tabular}

The mean age of the patients in this audit was 44.1 years $( \pm \mathrm{SD} 14.4, \mathrm{IQR}=33-54, \mathrm{Min} / \mathrm{Max}=$ $14 / 79$ years) and majority (64.8\%) were females.

Table 3: Patient characteristics

\begin{tabular}{|l|r|r|r|}
\hline $\begin{array}{l}\text { ASA score } \\
\text { I/II/III }\end{array}$ & Frequency & $\mathbf{\%}$ & $\mathbf{9 5 \% C I}^{*}$ \\
\hline I & 105 & 53.6 & $45.9-61.7$ \\
\hline II & 76 & 38.8 & $31.1-46.0$ \\
\hline III & 15 & 7.7 & $4.0-11.3$ \\
\hline Total & $\mathbf{1 9 6}$ & $\mathbf{1 0 0 . 0}$ & \\
\hline $\begin{array}{l}\text { Duration of } \\
\text { Surgery }\end{array}$ & & & \\
\hline$<1$ hour & 56 & 30.9 & $24.9-38.1$ \\
\hline $1-6$ hours & 122 & 67.4 & $61.3-73.5$ \\
\hline$>6$ hours & 3 & 1.7 & $0.0-3.9$ \\
\hline Total & $\mathbf{1 8 1}$ & $\mathbf{1 0 0 . 0}$ & \\
\hline
\end{tabular}

$* 95 \% \mathrm{CI}=$ Confidence Interval

The above group of patients had either an endotracheal tube or a supra-glottic airway device for the relevant surgical procedure. Data was missing in 15 data sheets regarding duration of surgery (14 in the ETT group and 1 in the SGA device group).

Table 4: Types of airway devices used for ventilation during general anaesthesia

\begin{tabular}{|l|r|r|}
\hline Type of Airway & Frequency & $\%$ \\
\hline Endotracheal tube(ETT) & 162 & 82.7 \\
\hline $\begin{array}{l}\text { Supra-glottic Airway } \\
\text { device(SGA) }\end{array}$ & 27 & 13.8 \\
\hline Not indicated & 7 & 3.6 \\
\hline Total & $\mathbf{1 9 6}$ & $\mathbf{1 0 0 . 0}$ \\
\hline
\end{tabular}

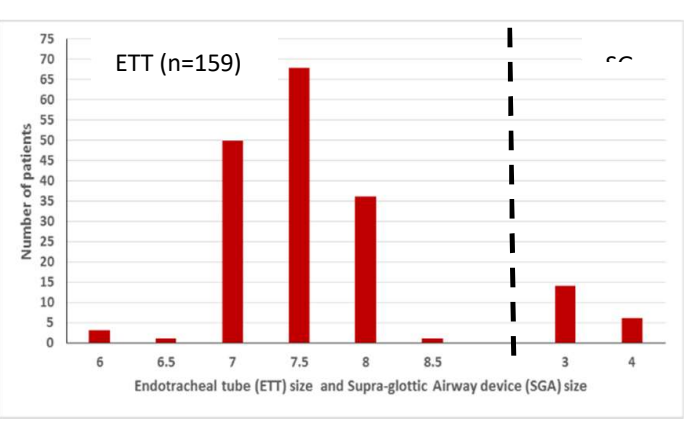

Figure 1: Distribution of various sizes of ETT \& SGA devices used during general anaesthesia (ETT size was not indicated in 3 questionnaires and the size of SGA device was not indicated in 7 questionnaires) 
Table 5: Personnel responsible for inflating the pilot balloon $(\mathrm{n}=196)$

\begin{tabular}{|c|c|c|}
\hline Initial cuff inflation done by & Frequency & $\%$ \\
\hline Anaesthetist (trainee) & 1 & .5 \\
\hline Medical officer (anaesthesia) & 10 & 5.1 \\
\hline Registrar in Anaesthesiology & 17 & 8.7 \\
\hline Consultant Anaesthetist & 1 & .5 \\
\hline Nursing officer & 4 & 2.0 \\
\hline Theatre supporting staff & 163 & 83.2 \\
\hline Total & 196 & 100.0 \\
\hline
\end{tabular}

Theatre supporting staff was responsible (83.2\%) for inflating the cuff (in both endotracheal tubes and supra-glottic airway devices) on most occasions.

\section{Initial cuff pressure value for endotracheal tubes (ETT)}

The initial cuff pressure value as a median was $30 \mathrm{cmH}_{2} \mathrm{O}$ [IQR: 25-45]. It ranged from $12 \mathrm{cmH}_{2} \mathrm{O}$ to $120 \mathrm{cmH}_{2} \mathrm{O}$.

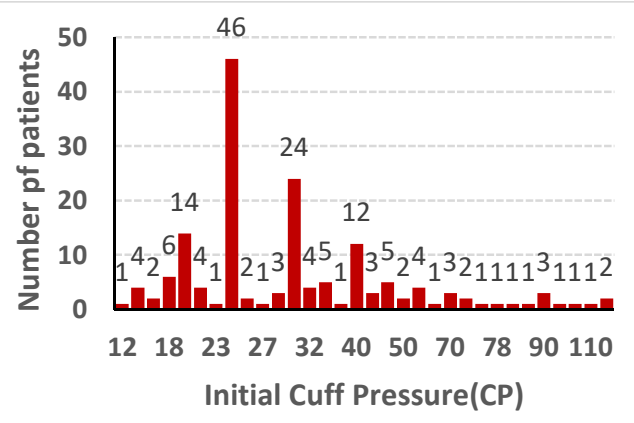

Figure 2: Distribution of cuff pressure in ETT $(n-162)$

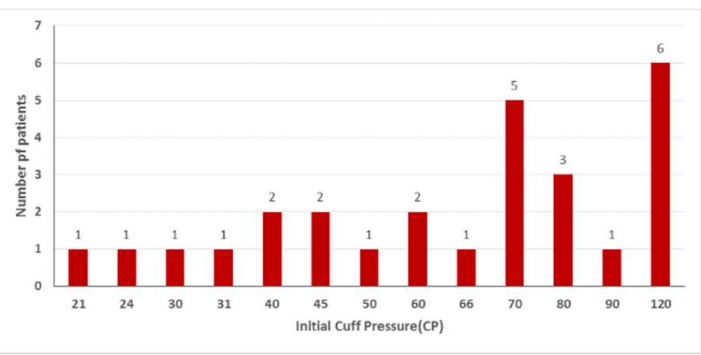

Figure 3: Distribution of cuff pressure in supraglottic airway devices $(n=27)$
Table 6: Measured Cuff Pressure expressed as Mean, Median, Standard Deviation and IQR in ETT and SGA devices

\begin{tabular}{|l|l|}
\hline Parameters & $\begin{array}{l}\text { cuff pressure } \\
\text { cmH2O }\end{array}$ \\
\hline ETT (n=162) & \\
\hline Mean & 35.25 \\
\hline Median & 27.50 \\
\hline Standard deviation & 21.09 \\
\hline IQR & $25-40$ \\
\hline Lowest value & 12.00 \\
\hline Highest value & 120.00 \\
\hline SGA (n=27) & \\
\hline Mean & 70.81 \\
\hline Median & 70.00 \\
\hline Standard deviation & 32.22 \\
\hline IQR & $45-90$ \\
\hline Lowest value & 21.00 \\
\hline Highest value & 120.00 \\
\hline
\end{tabular}

Table 7: Distribution of initial cuff pressure

\begin{tabular}{|l|l|l|l|}
\hline $\begin{array}{l}\text { Cuff } \\
\text { Pressure }\left(\mathbf{c m H}_{\mathbf{2}} \mathbf{O}\right)\end{array}$ & Frequency & $\mathbf{\%}$ & $\mathbf{9 5 \%} \mathbf{C I}$ \\
\hline ETT & & & \\
\hline$<20$ & 13 & 8.0 & $3.7-12.3$ \\
\hline $\mathbf{2 0}-\mathbf{3 0}$ & 95 & 58.6 & $52.2-65.9$ \\
\hline$>30$ & 54 & 33.3 & $26.0-39.7$ \\
\hline Total & $\mathbf{1 6 2}$ & $\mathbf{1 0 0 . 0}$ & \\
\hline SGA devices & & & \\
\hline$<60$ & 9 & 33.3 & $13.9-49.0$ \\
\hline $\mathbf{6 0}-\mathbf{7 0}$ & 8 & 29.6 & $14.4-43.9$ \\
\hline$>70$ & 10 & 37.0 & $21.7-61.6$ \\
\hline Total & $\mathbf{2 7}$ & $\mathbf{1 0 0 . 0}$ & \\
\hline
\end{tabular}

During the initial cuff pressure measurement $58.6 \%$ had pressures within the recommended level $\left(20-30 \mathrm{cmH}_{2} \mathrm{O}\right)$ for endotracheal tubes. $33.3 \%$ had cuff pressures of $>30 \mathrm{cmH}_{2} \mathrm{O}$ while $8 \%$ had cuff pressures of $<20 \mathrm{cmH}_{2} \mathrm{O}$.

In contrast to the above findings, the recommended cuff pressure values for supraglottic airway devices was achieved only in $29.6 \%$ and in $37 \%$ the cuff pressures were more than $70 \mathrm{cmH}_{2} \mathrm{O}$ which was an alarming feature. $33.3 \%$ had cuff pressure values less than recommended. 


\section{Relationship between various carrier gas combinations and cuff pressure values during general anaesthesia for ETT}

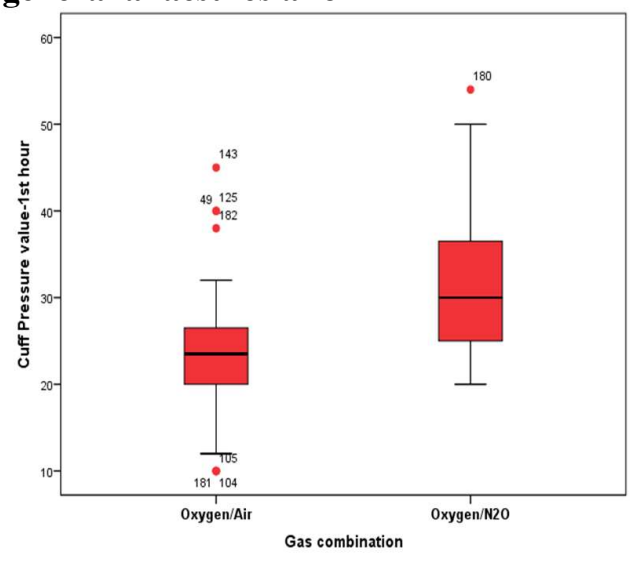

Figure 4: An exploratory graphic of cuff pressure values varying with different gas combinations at the end of first hour of surgery

The box-and-whisker plot depicts the median (horizontal line at the centre of the box), $25^{\text {th }}$ and $75^{\text {th }}$ percentiles and the range, of the data set for patients who had an ETT during surgery. Red dots indicate the outliers.

Oxygen/Air (mean, median $\pm \mathrm{SD}$ ) $=23.58$, $23.50 \pm 6.08$

Oxygen $/ \mathrm{N} 20$ (mean, median $\pm \mathrm{SD}$ ) $=31.88$, $30.00 \pm 9.44$

The median difference in gas combinations between (oxygen $+\mathrm{N}_{2} \mathrm{O}$ ) and (oxygen + air) on cuff pressure was significantly different $(\mathrm{z}=$ 4.507, $\mathrm{p}<0.001)$.

Use of $\mathrm{N}_{2} \mathrm{O}$ / Oxygen combination with time, resulted in an increased cuff pressure which may be due nitrous oxides property of increased solubility in relation to nitrogen

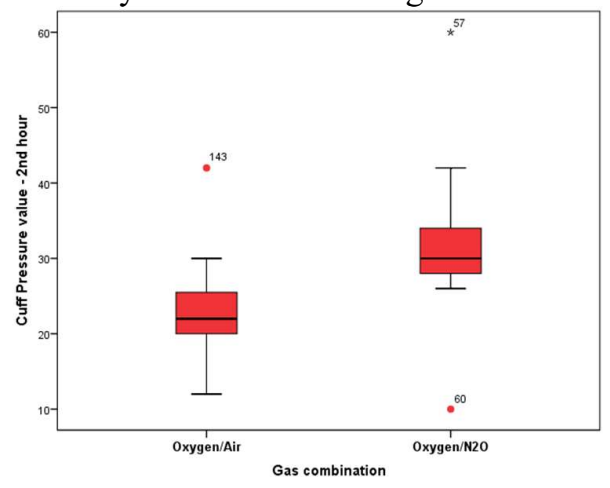

Figure 5: An exploratory graphic of cuff pressure values varying with different gas combinations at the end of second hour of surgery
Oxygen/Air (mean, median $\pm \mathrm{SD}$ ) $=22.34$, $22.00 \pm 5.51$

Oxygen/N20 (mean, median $\pm \mathrm{SD}$ ) $=32.00$, $30.00 \pm 12.65$

The median difference in gas combinations between (oxygen $+\mathrm{N}_{2} \mathrm{O}$ ) and (oxygen + air) on cuff pressure at the end of second hour of surgery was significantly different $(\mathrm{z}=3.309, \mathrm{p}<0.001)$.

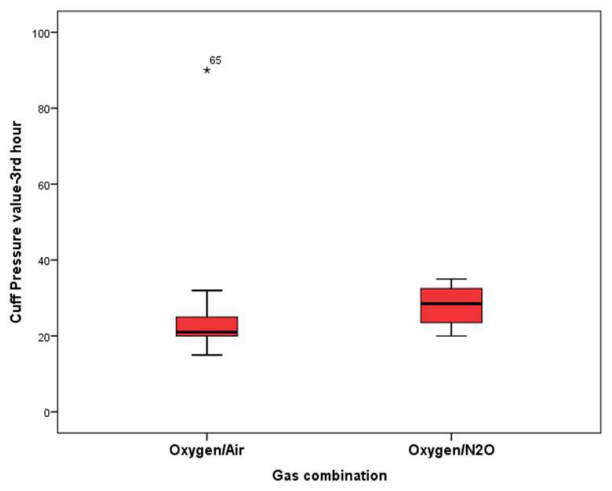

Figure 6: An exploratory graphic of cuff pressure values varying with different gas combinations at the end of third hour of surgery Oxygen/Air (mean, median $\pm \mathrm{SD}$ ) $=25.94$, $21.00 \pm 16.68$

Oxygen $/ \mathrm{N} 20$ (mean, median $\pm \mathrm{SD}$ ) $=28.00$, $28.50 \pm 6.28$

The median difference in gas combinations between (oxygen $+\mathrm{N}_{2} \mathrm{O}$ ) and (oxygen + air) on cuff pressure at the end of third hour of surgery was not significantly different $(\mathrm{z}=1.387$, $\mathrm{p}<0.16$ ).

Relationship of carrier gas \& cuff pressure during general anaesthesia expressed as a box-and-whisker plot for SGA devices at the end of first hour of surgery

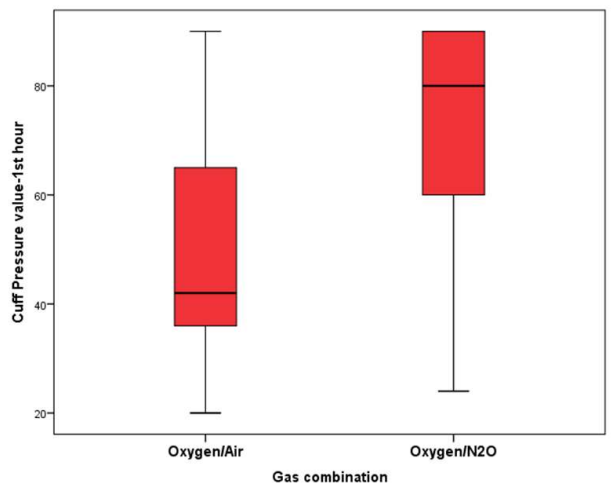

Figure 7: Relationship between cuff pressure values and different carrier gas combination at the end of first hour of surgery 
Most surgeries which used a supra-glottic airway device lasted for one hour.

Oxygen/Air (mean, median $\pm \mathrm{SD}$ ) $=50.60$, $42.00 \pm 27.31$

Oxygen $/ \mathrm{N} 20$ (mean, median $\pm \mathrm{SD}$ ) $=68.80$, $80.00 \pm 28.88$

On analysis of data the median difference in gas combination between (oxygen $+\mathrm{N}_{2} \mathrm{O}$ ) and (oxygen + air) on cuff pressure was not significant $(\mathrm{z}=0.952, \mathrm{p}=0.34)$.

Postoperative airway complications in the immediate recovery period were recorded only in 10 patients and majority had complained of sore throat (5) followed by hoarseness of voice (4) and blood- stained sputum (1). Most respondents had failed to provide an answer to the question on "immediate postoperative complications".

\section{Discussion and Conclusion}

Both endotracheal tube and supra-glottic airway device cuff pressures should be kept at an optimal level to facilitate ventilation and prevent gas leak from the lower respiratory tract. Optimal cuff pressures are also required to prevent leakage of bacterial pathogens around the cuff in to the lower respiratory tract $^{2}$ and aspiration under anaesthesia which can result in disastrous consequence to a patient undergoing surgery. One aspect of airway management is maintenance of an adequate cuff pressure in the endotracheal cuff. ${ }^{3}$ The same principle would apply for supra-glottic airway devices.

The current recommendation is to maintain the ETT cuff pressure $<30 \mathrm{cmH}_{2} \mathrm{O}$ to prevent tracheal injury. ${ }^{2}$ Thus the desirable limit to maintain the ETT cuff pressure during a surgical procedure is between $20-30 \mathrm{cmH}_{2} \mathrm{O}^{2}$ and should not exceed $35 \mathrm{cmH}_{2} \mathrm{O}^{4}$

The amount of air required to achieve the minimal recommended pressure of $20 \mathrm{cmH}_{2} \mathrm{O}$ is $2.6 \mathrm{ml}$ for a size $7.0 \mathrm{~mm}$ ETT and $3.3 \mathrm{ml}$ for $8.5 \mathrm{~mm}$ ETT. ${ }^{3}$

Although the pilot balloon cuff may be easily distensible in open air, when confined to the trachea a small increment in inflation volumes may produce high pressure ${ }^{5}$ and can result in tracheal mucosal damage and subsequent ischaemia and necrosis. ${ }^{4}$
Many anaesthesiologists would feel the pilot balloon after inflation as a manual control of cuff pressure and this is undoubtedly a method, which cannot be relied upon. Over-inflation of the ETT cuff has been well documented in many studies involving ICU patients ${ }^{6}$ and remains an avoidable risk factor for tracheal ischaemia and associated complications.

When the pressure exerted on the tracheal mucosa exceeds the mean capillary perfusion pressure of the mucosa it leads to numerous pathological changes such as ischaemia, inflammation, ulceration, tracheal necrosis, stenosis and rarely trachea-oesophageal fistula formation. ${ }^{6}$ Respiratory complications such as sore-throat, hoarseness and blood stained sputum can follow even short duration intubations of 1-3 hours. ${ }^{6}$ Rare complications such as nerve palsies have also been reported in the literature. ${ }^{7}$ Therefore to overcome such adverse events excessive pressures must be avoided in all patients requiring ETT intubation by objective measurements. ${ }^{4}$ Interestingly decrease in cuff pressure have also been noted over time more so with longer duration of intubation. ${ }^{3}$ This could predispose a patient to aspiration under anaesthesia.

The manufacturers of SGA devices recommend that cuff pressure should be $<60 \mathrm{cmH}_{2} \mathrm{O}$, however it is acceptable to use pressures between 60$70 \mathrm{cmH}_{2} \mathrm{O}$ in clinical practice. Intra operative cuff pressure of $<44 \mathrm{mmHg}\left(60 \mathrm{cmH}_{2} \mathrm{O}\right)$ is associated with reduced pharyngo-laryngeal complications by $70 \%$ compared to routine care without manometry. ${ }^{8}$ Incidence of sore-throat (42\%) and nerve injuries are well documented in the literature following over-inflation of the SGA device cuff during surgery. ${ }^{8}$

Best practice research evidence suggests that intra operative cuff pressure monitoring can avoid potential harm to a patient undergoing general anaesthesia with an ETT/SGA device in situ. Reasons for failure to reach standards such as ignorance of the staff regarding the need to measure cuff pressure and failure to measure cuff pressure regularly, ${ }^{4}$ can be overcome by regular reminders and education to the attending anaesthetist and healthcare personnel dealing with airway devices during surgery. 


\section{Acknowledgements}

I am grateful to Professor Anuja Abayadeera for critically analysing the audit proposal and to all postgraduate trainees in anaesthesiology who provided the relevant information to complete this preliminary audit.

\section{References}

1. Burri NR, Kumar P, Mendonca C. Intra-operating airway cuff pressure. British Journal of Anaesthesia 2013; 111:4

2. Lorente L, Blot S, Rello J. Evidence on measures for the prevention of ventilator associated pneumonia, European Respiratory Journal 2007; 30: 1193-1207

https://doi.org/10.1183/09031936.00048507 PMid: 18055704

3. Sole ML, Talbert S, Penoyer DA et al. Evaluation of an intervention to maintain endotracheal cuff pressure within therapeutic range. Am J Crit Care 2011; $\quad 20 \quad$ (2):109-118 https://doi.org/10.4037/ajcc2011661

PMid:21362715 PMCid:PMC3506174

4. Nightingale P, Griffiths H, Clayton JA. Tracheal tube cuff pressure. Raising the standard a compendium of audit recipes. Section 10. Critical Care Services. Royal College of Anaesthetists Audit Recipe Book third edition, 2012

5. Lewis FR, Schiobohm RM, Thomas AN. Prevention of complications from prolonged tracheal intubation. Am J Surg 1978; 135 (3): $452-7$ https://doi.org/10.1016/0002-9610(78)90083-1

6. Ghafouri HB, Saeedi H, Zadeh MY et al. Excessive endotracheal tube cuff pressure: is there any difference between emergency physician \& anaesthesiologist? Signa Viate 2012; 7 (2): $17-20$

https://doi.org/10.22514/SV72.102012.3

7. McHardy FE, Chung F. Post-operative sore throat: cause, prevention and treatment. Anaesthesia 1999; 54 (5): 444-53

https://doi.org/10.1046/j.13652044.1999.00780.x

8. Brimacombe J, Holyoake L, Kellar C et al. Pharyngolaryngeal, neck and jaw discomfort after anaesthesia with the face mask and LMA at high and low cuff volumes in males and females. Anaesthesiology 2000; 93: 26-31

https://doi.org/10.1097/00000542-200007000$\underline{00009}$ 